\title{
Understanding the structured processes
}

\section{followed by organisations prior to engaging in agile processes: A South African Perspective}

\author{
Nimrod Noruwana ${ }^{1}$ and Maureen Tanner ${ }^{2}$ \\ Department of Information Systems, University of Cape Town, South Africa.
}

\begin{abstract}
There appears to be a lack of knowledge on the phases South African (SA) organisations go through while adopting agile methods. As a means to address this gap, this study uncovered empirical evidence on the phases SA organisations go through whilst adopting agile methods as well as the disparities between agile prescriptions and the way SA organisations actually implement agile methods.

The data collected using a case study approach was analysed through the lens of Actor-Network Theory (ANT). The results reveal that there is no structured process for adopting agile methods and organisations go through various phases in their attempts to adopt agile methods. During the various phases, organisations face challenges which are culture as well as people related.

Through this study South African practitioners could now be aware that before adopting an agile methodology, there has to be a common understanding of the problems at hand and the envisioned solution. The findings also inform aspiring adopters in South Africa that adoption of the methods does not have to be as prescribed. They are free to adopt only those aspects the organisations need most.
\end{abstract}

\section{KEYWORDS}

Agile methods, Scrum, Actor-network Theory, Adoption

\section{INTRODUCTION}

In the modern world, organisations operate in uncertain and dynamic competitive environments. There are many sources of turbulence in these environments emanating from factors such as intensified global competition, reduced lead-time, reduced product life expectancy, diversified demand and new technologies [1]. In order to address these challenges, the agile approach to software development was introduced.

Agile methods of software development continue to gain popularity in South Africa. However, little has been said about the approach and its adoption challenges in the South African context. In practice, a few organisations are able to take on agile development approaches immediately and adopt them successfully over a short period of time; a full transition often takes a few years [2]. Furthermore,

\footnotetext{
${ }^{1}$ NRWNIM001@uct.ac.za

2 mc.tanner@uct.ac.za
}

it may be inappropriate for them to adopt all aspects of agile methods of systems development.

Although agile methods of systems development are believed to help improve the software development process, their adoption often encounters resistance. This resistance comes mainly from IT personnel [3]. Organisations may, therefore, be unsure of how to adopt agile methods i.e. the appropriate aspects to choose for their situation and how to foster enthusiasm in team members [4]. Organisations are also unsure of how to ensure that the whole of the development team does not succumb to the inherent desire of humankind to "resist change" [5].

There are other factors that could pose a challenge in the adoption of agile methods. These may be related to the process that organisations follow prior to the adoption, during the adoption and post adoption. These challenges may be based on a lack of understanding of the agile methodology being adopted or even aspects of it. In understanding the methodology, organisations need to know the 
aspects of the methodology that would address specific problems. Such information should therefore enable South African organisations to know and understand the benefits that a successful implementation of agile can bring.

The purpose of this study is therefore descriptive and explanatory; to examine and describe the phases that South African organisations go through during the process of adopting agile methods of systems development and explain how they may be dealt with in a successful adoption. The specific agile method under study is Scum. The results of this study may help to provide an in-depth understanding of the challenges that South African organisations experience before, during and after the adoption of agile systems development methods.

Actor network theory (ANT) has been used to trace the process that is followed in the adoption of agile methods. ANT in this study has revealed how actors align their interests through the moments of translation to form the network. The negotiations among actors while aligning their interests have revealed insights in their interactions during the process of adoption.

It has been found that there is limited literature on the adoption of agile methods in the South African context. This research has thus contributed to the agile software development body of knowledge. The gap identified was that there was no literature that discussed specific processes or frameworks followed in adopting agile methods. Results of this research study bridges that gap. The results in this research study have also revealed the extent to which the adoption of agile methods can help organisations to take a holistic approach to systems development.

Some of the recommendations coming out of this research study may provide a blueprint for ways in which Scrum as an agile method of systems development, can be adopted by organisations similar to the one studied. These organisations can benefit by improving on what has been done, avoiding the mistakes that have been made and making use of recommendations. Organisations that shun implementation of agile methods for fear of project failures may learn from the findings in this research study.

\section{LITERATURE REVIEW}

In order to bring the research study into perspective, a literature survey was undertaken. This section therefore, gives an overview of the literature on agile methods of systems development in general and on Scrum in particular. Adoption of Scrum is the specific agile methodology under study in the research.

According to the Oxford dictionary, "agile" is the ability to move quickly and easily. This definition does not look at any specific application of the word. [6] has introduced a definition that applies to the general business environment. He states that agile is the ability to respond to change in order to profit in a dynamic business environment. This definition refers to any business environment. Our main interest here is to understand what agile means in the management of systems development activity. [7] see agile as a humanistic and collaborative style of systems development which promotes and encourages the continual realignment of development goals with the needs and expectations of the customer.

In the late 1980 s to early 1990 s, agile software development methods emerged with rapid application development (RAD) being the first $[8,9$, 10]. From this method came extreme programming (XP) [11], Scrum [12], feature driven development (FDD) with Jeff De Luca and Peter Coad being the pioneers [6] and dynamic systems development method (DSDM) [13, 14].

Agile methods deliver working software within a period of two to four weeks, and thus allow organisations to quickly seize opportunities presented by dynamic business environments [15, 16]. Agile methods are suitable for market driven environments. The methods are also helpful in situations where there are frequent systems requirement changes. According to [17], agile methods also address rapidly changing business requirements by focusing on the people factor in terms of amicability, talent, skill and communication. [18]identifies rapid learning, early return on investment, satisfied stakeholders, increased control, and responsiveness to change as some of the benefits of agile methods. In contrast, traditional systems development methods, which are plan-driven, lack the flexibility to adjust to frequent systems requirement changes in the course of the development process [15].

There is a variety of agile approaches to system development to select from. However, what the approaches promise differ. Most organisations do not follow agile methods exactly as prescribed by the literature. In most cases method selection is based on the nature and size of projects [19]. This study focused on Scrum. Scrum is therefore, discussed in the following Sub-section. 


\subsection{Scrum}

The term "Scrum" is adapted from the game of rugby as the strength of the scrum comes from the strength of the teamwork that is revealed by the rugby team [20]. Scrum is described in five steps.

Step 1. The product owner shares the product vision with the team that will be part of the project. This takes the form of a prioritised list of what is required, ranked in order of business value, with the highest value items at the top. This list is referred to as the product backlog. The product backlog exists and evolves over the lifetime of the project. The backlog includes a variety of items, such as features, development requirements, exploratory work and known bugs.

Step 2. The aspect in this step is the sprint. A sprint is two to four weeks long. This is a period during which a Scrum team should produce working software. At the beginning of each sprint, there is a sprint planning meeting. The meeting is divided into two parts. In the first part, the product owner and Scrum team, facilitated by the Scrum master, review the product backlog, discussing the goals and providing the Scrum team with insight into the product owner's thinking. In the second part, the Scrum team selects the items from the product backlog to commit to complete by the end of the sprint, starting with the items that are of highest priority and working down the list in order. The team decides how much work they will commit to complete, rather than having it assigned to them by the product owner.

Step 3. Once the sprint is started, the Scrum team engages in daily stand-up meetings at an appointed time and everyone on the Scrum team is obliged to attend. The meeting lasts about 15 minutes. During the stand-up meeting, one by one, each member of the team reports just three things to the other members of the team: (1) What they are busy with,

(2) what they will do before the next meeting and

(3) what the obstacles are. The Scrum master notes the obstacles and tries to resolve them after the meeting. There is no discussion during the daily stand-up meetings, just the reporting of the three key pieces of information.

After the meeting, the team updates the amount of time remaining to complete each of the tasks on the sprint backlog. This information is recorded on a graph called the sprint burn down chart. The chart shows the amount of work remaining before the team's commitment is completed as well as the team's actual progress towards its goal. The work is measured in hours or days.
Step 4. At the end of a sprint, there is the sprint review where the team demonstrates what it has built. Present at this meeting are: the product owner, team members, the Scrum master, customers, stakeholders, experts, executives and anyone interested.

Step 5. Following the sprint review, the team gets together for the sprint retrospective. It is an opportunity for the team to discuss what is working and what is not, and agree on changes. The Scrum team, the product owner, and the Scrum master all attend, and a neutral outsider facilitates the meeting. Sprints continue until the product owner decides the product is almost ready for release, at which point there may be a "release sprint" for final integration and testing in preparation for launch. If the team followed good development practices along the way, with continuous integration and effective testing during each sprint, there can be little clean up required in the release sprint.

\subsection{Challenges to adopting agile methods}

Introducing agile methods in an organisation can be a challenging task [21]. This study specifically focused on Scrum but it is important to understand the challenges associated with the adoption of agile methods as a whole. These are summarised in Table 1.

\begin{tabular}{|l|l|}
\hline Challenge & Description \\
\hline Culture & $\begin{array}{l}\text { Difficult to change the } \\
\text { existing culture }\end{array}$ \\
\hline $\begin{array}{l}\text { Lack of } \\
\text { Structured } \\
\text { Approach }\end{array}$ & $\begin{array}{l}\text { Makes the process of } \\
\text { adopting agile systems } \\
\text { difficult and exposes it to } \\
\text { failure. }\end{array}$ \\
\hline $\begin{array}{l}\text { Assigning of New } \\
\text { Roles }\end{array}$ & $\begin{array}{l}\text { Team members find it } \\
\text { difficult to change the roles } \\
\text { they are used to. }\end{array}$ \\
\hline Slow buy-in & Resistance to change \\
\hline $\begin{array}{l}\text { Developers } \\
\text { Opposed to Pair } \\
\text { Programming }\end{array}$ & $\begin{array}{l}\text { Developers prefer to be } \\
\text { private about their } \\
\text { knowledge. }\end{array}$ \\
\hline $\begin{array}{l}\text { Resistance to } \\
\text { Team Evaluation }\end{array}$ & $\begin{array}{l}\text { Individuals want to be } \\
\text { recognised as individuals for } \\
\text { their contributions. }\end{array}$ \\
\hline
\end{tabular}

Table 1. - Challenges of Adopting Agile Methods

[21]points out that culture is rarely considered when adopting new systems development methods and yet it plays a major role. It therefore, makes sense to understand the adoption of agile methods in the South African context and culture. However, there is no structured approach to agile systems development adoption in the public domain [22], a 
scenario which makes the process of adopting agile systems difficult. [22] further identify some issues that need to be considered when organisations consider adopting agile methods. These issues include readiness for the agile adoption, understanding of the agile practices needed for adoption and anticipation of potential difficulties in the process.

Agile adopters usually struggle with assigning new roles to management, the inability of developers to handle the transition from legacy to agile and negotiating with management on the issues pertaining to adoption $[23,16,24]$. There are also problems relating to resistance to change that would prevent organisations from adopting agile methods [16]. In contrast with what agile methods prescribe, [25, in a study on the influence of culture in the adoption of agile methods, found that organisations need to choose software development methods that suit their culture instead of changing their culture to accommodate the methodology.

Adoption of agile methods is accompanied by a number of challenges. These challenges include slow buy-in, developers being opposed to pairprogramming, the threat of scope creep, the difficulty of evaluating and rewarding individual performance, the need for significant on-site customer involvement, management support, competent managers and developers, and extensive training [26]. However, it is normal that the adoption of new systems development methodology face some challenges $[26,14]$. This study seeks to unravel the various processes followed by organisations prior to adopting an agile method like Scrum. It is thought that the processes and stages of adoption emerge because of the inherent challenges accompanying agile methods adoption. The study has been undertaken within the South African context and the findings might be useful to similar South African organisations seeking to embark on an "agile adoption" journey. However, it is believed that the findings might also benefit other non-SouthAfrican organisations as they would much likely face similar issues.

\subsection{The use of agile methods in South Africa}

As the study is set within the South African context, a brief overview of the use of agile methods in South Africa is provided. [27] studied agile methods in a South African context. This study investigated stakeholder satisfaction in organisations that have adopted agile methods of systems development. The study found that smaller teams of up to five members brought about greater stakeholder satisfaction than larger teams. The findings also revealed that stakeholders were more receptive to certain aspects of agile methods. Iterative development, collective ownership and continuous integration brought the highest satisfaction to stakeholders while TDD and face-to-face communication were not well received.

In South Africa, problems being experienced by software development companies include late software releases, cost overruns, insufficient requirements and documentation and resource constraints [28]. It has also been found that a lack of understanding of user requirements to some extent is a cause of problems.

This research sought to provide answers to the following research questions:

- How do organisations prepare for the adoption of agile methods?

- What phases do organisations go through during the implementation of agile methods of systems development?

- What aspects of agile methods do organisations follow and why?

\section{RESEARCH METHODOLOGY}

The research adopted an empirical, qualitative and interpretive stance. One in-depth exploratory case study was employed as a research strategy. According to [29], this method of research applies an approach where the detailed investigation of one or more organisations, or groups within organisations, is involved in the study. The researchers did not have any involvement with IM prior to the case study. IM was identified and selected as a case because of their use of Scrum for the management of their software projects. IM was also conveniently located in Cape Town, Western Cape, thus making access to the organisation's premises easy for the researchers.

\subsection{Data collection}

As the aim of the research was to gain a deeper understanding of the social processes involved in the adoption of agile methods, data was collected through qualitative means which included semistructured interviews, direct observations and field notes. Triangulation was then performed to verify the credibility of the data as well as validate the research findings.

Data collection and analysis were guided by the lens of Actor-Network Theory (ANT) [30, 31, 32, 33]. [34] and [35] describe ANT as a framework and a systematic way for considering the infrastructure surrounding technological achievements by 
assigning equal status to both human and nonhuman elements.

Interviews followed an interview guide. The guide comprised four sections structured according to the research questions: demographics, attitude of organisation towards technology, preparation for adoption and the adoption process. The case (sample) selection was purposive. However, the interviewees were not identified prior to the beginning of the study, owing to the fact that the research employed ANT. The interviewees were identified as the network was being traced [36].

\subsection{The Actor-Network theory}

ANT provides a bridge between the social-technical divide by denying that purely technical or purely social relations exist in isolation [37]. ANT attempts to facilitate an understanding of the construction and transformation of networks made of heterogeneous elements e.g. organisations, agents, artefactsetc[38].

An actor in a network is independent and can resist influence from other actors [36]. A network exists by use of a binding referred to as moments of translation. When organisations adopt a new technology, they (the organisations) go through moments of translation. In this study, emergence and/or formation as well as maintenance of networks in the adoption of agile methods in systems development are explored. [39] identifies problematisation, interessement, enrolment and mobilisation as the bond that holds the network together. The moments of translation are briefly discussed in the following sub-sections.

\section{- Problematisation}

According to [37], the stage of problematisation is where the key actor may want to change the way things are done. Accordingly, the key actor's interests are revealed and shared with potential actors and attempts to create alliances with other actors with similar objectives. However, power structures in a network may affect the ability of some actors to oppose the problematisation of technology adoption [36]. For instance, if a chief information officer is the main actor in the network of adoption of agile methods, the developer and end users may not be able to contest the initial problematisation. This may be due to his power in the network which is due to the position he holds in the organisation.

\section{- Interessement}

At this stage the key actor tries to impose his identity on other actors that have become part of the alliance thus far [32]. Interessement may involve some compromise, persuasion and seduction in order to get actors interested in roles proposed to them. [36] indicate that the power structures present in the network also affect some of the actors who were opposed to the initial problematisation. This compels them to become part of the network. This is known as the obligatory passage point (OPP).

\section{- Enrolment}

This is the stage where the actors accept the roles proposed to or imposed on them by the key actor and begin to align their interests with those of the main actor. Roles are defined in the evolving actor network and actors are convinced to become part of the network where the objectives of the main actor can be pursued. For the process of enrolment to succeed, the main actor needs to capture the other actors [40].

\section{- Mobilisation}

Mobilisation, the last of the moments of translation, is where opposition is silenced and only spokespersons are permitted to speak on behalf of the network. The objective is to stabilise the network and maintain relationships. The main actor continually convinces actors that their interests are in sync and controversy no longer exists [41].

\subsection{The case description}

The study was conducted at IM. IM is a South African investment management organisation established in 1973. It has grown from a sole proprietorship to one of the largest privately owned, independent asset management companies in Southern Africa with offices in the Cape Town, Namibian and Botswana. IM currently employs a total of 800 people.

\section{- IM business operations}

IM main purpose is to assist its clients to build longterm wealth by buying companies whose share price is less than their intrinsic value. The intrinsic value is what a prudent businessman would pay to buy the whole company. This involves constant study of the market environment.

IM deals with institutional clients such as pension funds, financial advisors and investors. The company runs seven unit trust funds as well as a linked investment platform. IM business strongly depends on IT which is a business enabler and not a competitive advantage. It is therefore imperative for IM to embrace up-to-date technology that would facilitate prompt response to seize opportunities that prevail in the market.

IM's business is divided into five functional areas referred to as domains. Domains are departments which carry out particular business functions. Table 2 summarises the five domains. 


\begin{tabular}{|c|c|}
\hline $\begin{array}{l}\text { Domain } \\
\text { Name }\end{array}$ & Domain Description \\
\hline $\begin{array}{l}\text { Online } \\
\text { Domain }\end{array}$ & $\begin{array}{l}\text { The main purpose of this domain, } \\
\text { whose head is referred to as the } \\
\text { online domain owner, is to } \\
\text { improve online service provision } \\
\text { to clients. This is the domain that } \\
\text { adopted agile. }\end{array}$ \\
\hline $\begin{array}{l}\text { Customer } \\
\text { relationship } \\
\text { (CRM) } \\
\text { domain }\end{array}$ & $\begin{array}{l}\text { This domain is responsible for } \\
\text { building long-term relationships } \\
\text { with customers. Their focus is on } \\
\text { customer loyalty. }\end{array}$ \\
\hline $\begin{array}{l}\text { Business } \\
\text { process } \\
\text { management } \\
\text { (BPM) } \\
\text { domain }\end{array}$ & $\begin{array}{l}\text { The BPM domain allows for } \\
\text { increasing flexibility to meet } \\
\text { changing external demands. They } \\
\text { monitor speed of responsiveness } \\
\text { to customer demands. The BPM } \\
\text { domain continuously revise } \\
\text { processes to facilitate the } \\
\text { reduction of costs, increased } \\
\text { speed of product and service } \\
\text { delivery reliability, and address } \\
\text { the quality of products and } \\
\text { services in terms of their } \\
\text { consistency and capability. }\end{array}$ \\
\hline $\begin{array}{l}\text { Invest } \\
\text { management } \\
\text { domain }\end{array}$ & $\begin{array}{l}\text { This domain is responsible for } \\
\text { making decisions on investment. } \\
\text { It assists clients to build long-term } \\
\text { wealth. It constantly studies the } \\
\text { market to take advantage of } \\
\text { opportunities that would } \\
\text { maximise their client's wealth } \\
\text { within a period of four years. }\end{array}$ \\
\hline $\begin{array}{l}\text { Business } \\
\text { intelligence } \\
\text { (BI) domain }\end{array}$ & $\begin{array}{l}\text { This domain helps the } \\
\text { organisation to make better } \\
\text { business decisions to improve } \\
\text { company performance. The } \\
\text { domain has a more comprehensive } \\
\text { knowledge of the factors affecting } \\
\text { the business, such as metrics on } \\
\text { sales, production and internal } \\
\text { operations. }\end{array}$ \\
\hline
\end{tabular}

\section{- The Role of IT at IM}

IM considers IT as a business enabler which facilitates rapid response to market changes. Thus, most of the organisation's annual budget is spent on IT. Before the adoption of Scrum, the quality of the systems implemented and upgraded left a lot to be desired within IM. The IT department was not delivering as expected and therefore, it was considered unpredictable and unreliable. These were the problems that triggered the investigation of into new methods of systems development for the online domain.

Prior to the adoption of Scrum, the online domain had twenty three systems development team members who had specialised skills with no multiskilling. Communication among these groups of specialists was very limited. The team only got together when they had their weekly project meetings. The systems development team was operating as team of teams grouped according to their specialisation. The online domain did not deliver the expected business value even though it was understood that IT was the most significant part of the business.

IT is the most significant part of the business. It is the area where IM spends most money each year. We see it as a business enabler. This business cannot survive without IT. It would not be able to respond to the market quickly. It is imperative that we deliver good quality technology to the business fairly frequently to keep up with the market changes (Online Domain Owner: IM).

These problems triggered the need for a more reliable software development approach. Scrum was discovered to be a suitable alternative.

\section{- Background of Scrum at IM}

Scrum in IM was first tried on a software upgrade project in an attempt solve the issues experienced in the Online Domain. Initially, a home-brewed methodology that failed was adopted to resolve the persistent problems. The failed project was meant to upgrade the Decalog system used to administer IM clients' assets. The team eventually settled on adopting Scrum which also initially failed due to lack of Scrum expertise; the development team attempted adopting Scrum without involving a Scrum consultant. The adoption of Scrum only succeeded after the second attempt upon involving a Scrum consultant who guided the team throughout the implementation process.

\section{DATA ANALYSIS}

This section describes how IM progressed through the different stages of inscription, translation and irreversibility during the Scrum adoption process. The Section is set out by introducing the actors in Table 3.

Before Scrum was introduced, the call centre at IM was congested with calls from clients, even though an internet functionality was available. The only other viable option available to clients in order to bypass the call congestion problem was to physically visit the IM offices. There was a common 
understanding that there were delays between the time functionalities were requested and delivered. The common understanding facilitated the online domain owner's problematisation to the business analysts. An alliance between the actors was therefore, easily formed.

"I think we've improved a lot now that we've started using Scrum, because with the waterfall approach there was a big delay between business requests and functionality delivery" (Business Analyst: IM).

The online domain owner, the head of the online channel, was the key actor during the adoption of Scrum. The key actor's main interest was to deliver easy-to-use website functionalities. This included new functionality, enhancements, fixes, the operational management of the website and internet self-service functionalities for IM's clients. The key actor, the online domain owner, wanted to improve the domain's service delivery to the business.

\subsection{Introducing the Actors and Networks Identified}

In analysing this case study a total of seventeen actors were identified as shown in Table 3. In some instances actors were black boxed for simplicity. This is because the different actors who do similar work would tend to share similar views, for instance developers.

\begin{tabular}{|l|l|}
\hline Actor & Description of role \\
\hline $\begin{array}{l}\text { Online domain } \\
\text { owner }\end{array}$ & $\begin{array}{l}\text { Responsible for the online } \\
\text { functional area }\end{array}$ \\
\hline $\begin{array}{l}\text { Business analysts } \\
\text { (boxed) }\end{array}$ & $\begin{array}{l}\text { Gather business requirements, } \\
\text { map business processes and } \\
\text { produce functional } \\
\text { specifications }\end{array}$ \\
\hline $\begin{array}{l}\text { Developers } \\
\text { (boxed) }\end{array}$ & $\begin{array}{l}\text { Code the required } \\
\text { functionality and produce } \\
\text { working software }\end{array}$ \\
\hline $\begin{array}{l}\text { Network } \\
\text { administrators } \\
\text { (boxed) }\end{array}$ & $\begin{array}{l}\text { Ensure that there is } \\
\text { connectivity with no } \\
\text { interruptions in the network }\end{array}$ \\
\hline Testers (boxed) & $\begin{array}{l}\text { Test the piece of software } \\
\text { developed and ensure that } \\
\text { software is according to the } \\
\text { business requirements and is } \\
\text { free from errors and bugs. }\end{array}$ \\
\hline Scrum & $\begin{array}{l}\text { The new software } \\
\text { development methodology } \\
\text { adopted. }\end{array}$ \\
\hline The CIO & \begin{tabular}{l} 
Manages the information \\
\hline
\end{tabular} \\
\hline
\end{tabular}

\begin{tabular}{|l|l|}
\hline & $\begin{array}{l}\text { needs of the business through } \\
\text { technology. Ensures that the } \\
\text { business has everything it } \\
\text { needs to get the right } \\
\text { information at the right time at } \\
\text { the right place. }\end{array}$ \\
\hline Scrum consultant & $\begin{array}{l}\text { The external resource hired to } \\
\text { guide the adoption process. }\end{array}$ \\
\hline $\begin{array}{l}\text { The business } \\
\text { (boxed) }\end{array}$ & $\begin{array}{l}\text { Users and business managers } \\
\text { who ultimately use the } \\
\text { systems to service clients. }\end{array}$ \\
\hline $\begin{array}{l}\text { Waterfall } \\
\text { methodology }\end{array}$ & $\begin{array}{l}\text { The traditional method of } \\
\text { systems development to be } \\
\text { phased out at IM }\end{array}$ \\
\hline $\begin{array}{l}\text { Database } \\
\text { Administrator } \\
\text { (Boxed) }\end{array}$ & $\begin{array}{l}\text { Responsible for administering } \\
\text { database servers; ensuring that } \\
\text { servers are always up and } \\
\text { running and are backed-up. }\end{array}$ \\
\hline $\begin{array}{l}\text { Project } \\
\text { Administrator }\end{array}$ & $\begin{array}{l}\text { Performs all the administrative } \\
\text { activities of the project. }\end{array}$ \\
\hline $\begin{array}{l}\text { Support } \\
\text { Consultants } \\
\text { (Boxed) }\end{array}$ & $\begin{array}{l}\text { Responsible for supporting the } \\
\text { business in terms of the } \\
\text { systems support. }\end{array}$ \\
\hline $\begin{array}{l}\text { Change Managers } \\
\text { (Boxed) }\end{array}$ & $\begin{array}{l}\text { Encourage acceptance of } \\
\text { change. They deal with } \\
\text { resistance to change by } \\
\text { applying strategies that would } \\
\text { ensure that change is accepted. }\end{array}$ \\
Manages the project. \\
\hline $\begin{array}{l}\text { Project manager } \\
\text { Specialists } \\
\text { (Boxed) }\end{array}$ & $\begin{array}{l}\text { Provide guidance with regards } \\
\text { to the software product in use. } \\
\text { These are experts in software } \\
\text { product knowledge. }\end{array}$ \\
\hline
\end{tabular}

Table 3 - Identified Actors in the Network

\subsection{First attempt at problematisation at IM}

The online domain owner, tried to impose his identity on the systems development team to start thinking about better ways of developing software to address issues around predictability, quality and productivity. This action constituted problematisation. The online domain owner, the key actor, ensured that the problem was acknowledged by everybody on whom it impacted. $\mathrm{He}$ was attempting to create an alliance with the entire systems development team.

In response to the key actor's problematisation, the systems development team attempted to develop its own methodology which subsequently failed. Some actors were seizing the opportunity to pursue their own interests without seeing the big picture, as quoted below. This was a clear indication that problematisation was failing. 
“.... When the new home-brewed methodology was being implemented I had to make it a point that I had a say in the whole matter because it would affect me. Apparently there were a few of us who had the same feeling." (Developer: IM).

The probable reason for this failure was the structures and powers that were already in the network. It might also be the case that even though the online domain owner tried to problematise his interest on the rest of the team, he allowed the situation to turn around and seem like a bottom-up approach. This is the situation where employees lower in the hierarchy drive the initiative. As opposed to the top-down approach, the problem with bottom-up approach is that too many actors become active participants in the network and this can give rise to chaos was in the case of the homebrewed methodology.

Even though there was a clear overall objective of delivering good quality software, there was no consensus among the actors in the network as to how the methodology would be used. In some cases there was resistance to change which brought about conflicts within the team; consequently, the actor network was very unstable. Subsequently, it became very difficult for the online domain owner to manage the situation. The project was consequently abandoned after six months and the team reverted to the old waterfall method.

It is also important to note that the waterfall method of systems development had little or no opposition in the network and therefore, at this stage quite, a strong actor in the network. The waterfall method of systems development managed to problematise its interests on the already existing network of actors and succeeded. The new methodology was, therefore, abandoned and the team reverted to the waterfall method of systems development.

"In the beginning we thought we were quite agile, but it turned out that we were not. We started looking at alternative ways of developing software. We even went to an extent of attempting implementing our own methodology. This was all around the quality of software that was produced but we did not succeed", (Domain owner: IM).

The failure of this problematisation was due to the fact that there were conflicting interests between human and non-human actors complicated the matter further for the key actor. It was challenging for the key actor to manage interests of human actors around those of non-human actors.

\subsection{Second Attempt of Problematisation at IM}

The second attempt of problematisation started three months after the first one had failed. This was in response to an urgent need to find a solution to the problems experienced at IM which had by then worsened. An urgent solution was needed to quickly rescue the situation; the quality of software needed serious attention. The call centre was flooded with calls since software upgrades were failing and functionality that had worked before was also failing. The team was neither motivated nor cohesive. There was tension in the team.

On reading a Gantt head IT Newsletter, the online domain owner came across Scrum that caught his interest. Gantt head was a short lived non-human actor in the network; it only appears in the network to introduce Scrum to the online domain owner. The online domain owner introduced Scrum to the development team as an option to resolving the systems development problems. Scrum, therefore, became a significant non-human actor in the network.

An IS team composed of system developers, business analysts, project manager, etc, read books about scrum and tried to implement it. As was the case with the home-brewed methodology, this attempt ended up in long meetings and debates trying to decipher the scrum discourse from books. Finally, the team was introduced to Scrum Consulting, a company that deals with coaching, training and consulting work on Scum methodology. Scrum consulting allocated a Scrum consultant to work with IM though out the Scrum Implementation.

Initially, the Scum consultant and the online domain owner seemed to share the same role of key actor in the network. However, as the Scrum consultant became more involved in the network becoming more dominant, he consequently inherited the role of the key actor. Due to his experience and role, the Scrum consultant was the most influential actor in the Scrum implementation. The consultant problematised his interests by presenting to the actors already in the network detailed steps on how Scrum works. Most actors were in support of the interests of the key actor (Scrum consultant) evidenced by the quotation below.

"Scrum consultant provided expertise in Scrum and provided the organisation an opportunity to get going with the adoption of Scrum", Domain owner: IM.

After the presentation the Scrum consultant made, interests of the actors grew stronger than before due to the fact that Scrum methodology was tested and 
proved to be working. The fact that a consultant would guide the team was seen as "a big milestone in the process of the adoption of Scrum". This can be seen as ensuring that problematisation succeeds.

In continuing with the process of problematisation, the network was extended by the problematisation of the chief information officer (CIO). The online domain owner together with the Scrum Consultant problematised their interest to the CIO through a series of meetings and PowerPoint presentations. See comment by the CIO below:

"This is truly something that we needed in this organisation. This seemed like a methodology which could address many of our problems" (CIO: IM).

At this stage the network was made up of the systems development team (three system developers, four business analysts, two database administrators, two system architect, two testers, project administrator, two support consultants, two change managers, a project manager and two product specialists), the online domain owner, the $\mathrm{CIO}$ and the executive team, the business, Scrum consultant, Scrum as a methodology and the waterfall methodology.

Unlike in the first attempt, the online domain owner in his the strategy utilised the power structure in IM. He problematised the CIO and the executive team first. The CIO was responsible for funding the implementation and also for driving the implementation by communicating the new envisaged approach of systems development to the rest of the business. It was therefore inevitable that there was buy-in from the CIO. Once the $\mathrm{CIO}$ and the executive team joined the network in the adoption of Scrum, there could be very little resistance from other stakeholders during the problematisation process. This was due to the power structures present in the network that influenced some of the actors who were opposed to the initial problematisation[36]. This made Scrum become the obligatory passage point (OPP).

In his presentations to the $\mathrm{CIO}$ and the executive team, the Scrum Consultant gave details of how Scrum works and also explained the changes needed for Scrum to be successfully implemented. Thereafter, the CIO, in the company of the Scrum consultant, formally introduced scrum to all internal stakeholders including the affected business areas and the systems development team. The Scrum Consultant was invited to the formal Scrum introduction to address queries from the stakeholders. In his introduction, the CIO called on everyone to support the new approach to systems development. By this introduction, the CIO was re- emphasisingproblematisation to the rest of the actors. He was officially confirming that Scrum would be used, thus making it the OPP.

The CIO sent weekly bulletins to the entire organisation informing employees of the progress of Scrum implementation. This ensured that actors became strong in the network, weakening any possible resistance from potential actors. Problematisation in this case was continuous and the network moved from strength to strength. At this stage all major stakeholders had become problematised. This is line with [34] who states that conflicting interests among stakeholders must be absent for the network to be strong which this network was indeed doing.

\subsection{Interessement}

As stated by [42], interessement is the persuasion of actors to get interested in becoming part of the network. Interessement may or may not succeed. The success of interessement results in enrollment [42].

The online domain had recently in-sourced some of the systems development work that had previously been outsourced and the systems development structure and processes were, therefore, new. The systems development team was also open to new ideas. This made it easy for the Scrum consultant to introduce a new way of thinking.

Different strategies can be used in the interessment phase. In the case of the online domain owner, he tried to involve the development team in trying to come up with a methodology that could be suitable for addressing problems experienced in the systems development environment. Scrum was thus proposed as a solution by the online domain owner, and he attempted to shift the software development process towards a more light-weight approach, through the use of lean documentation. Even though this was also used as problematisation, it also constitutes interessment. The actors in the systems development team were locked in place by virtue of acting on the online domain's request.

After the official introduction of Scrum by the $\mathrm{CIO}$, there was some resistance from some of the members of the development team. The actors resisting to the adoption of Scrum or some aspects of and how they were addressed are detailed in the following sub-section.

Resistance from Business Analysts - The Business Analysts, as was the case with the first attempt of problematisation, objected to the aspect of lean documentation as they did not regard this as being possible. They still wanted to generate sixty 
pages of specifications. The quotation below exemplifies the resistance.

"There was one thing that I thought would not change, the need to have the complete business requirement specification before you start development. As business analysts we were totally against lean documentation" (Business Analyst: IM).

Resistance from Old Experienced Employees This is a group of people who had many years of experience in the waterfall methodology. They did not see any benefit in delearning Waterfall methodology and learn Scrum when they only had a few years left before their retirement. Due to resistance to change, one employee who was close to retirement opted for early retirement. He was not willing to accommodate change. The retirement of this employee constitutes failure in interessement. One experienced developer was quoted as follows:

"My colleague decided to take early retirement because he was left with only two years before he could retire" (Old \& Experienced Developer).

Resistance against sitting arrangement - Office space had to be rearranged to accommodate and encourage face-to-face communication, pairprogramming and quick problem solving. This was resisted as well. This was a culture issue and had to be dealt with. The culture at IM was that people were provided their working space for personal comfort and privacy. Traditionally at IM, each employee was provided with their own cubicle for privacy. Some had pictures, plants, soft music, etc in their cubicle. They, therefore, perceived the rearrangement as invasion of their privacy. This is evidenced by the quotation below. Intense interessement strategy had to be applied in order to convince this group of people that this was for the benefit of the team performance.

"I was not against Scrum, but the rearrangement business drove me insane. I needed space and privacy, in fact I still do" (Developer: IM).

\section{- Dealing with Resistance}

In dealing with resistance, a number of interessement strategies were used. Corridor salesmanship, driven by the Scrum consultant, was used. Due to the corridor salesmanship, Scrum became the talk of the entire organisation. Informal discussions on Scrum would erupt among the system development team members, which presented opportunities for interessement by clarifying misconceptions. Another major act of intressement strategies was the provision of training by the Scrum consultant to all actors that would play a role in Scrum. The course clarified the Scrum role players, the key principles of Scrum, Scrum tools and the process.

After the Scrum training, the business analysts, who were quite resistant to the introduction of lean documentation, were made to understand how documentation was done in Scrum. In dealing with the resistance the Scrum Consultant kept on emphasizing the need for the team to remain focused on the needed functionality and not everything. The Scrum consultant also indicated that it was important to have just enough documentation to get the required functionality in production. The consultant drew the attention of the team on priorities by drawing their attention to the requirements of the stories in a sprint. The business analysts were made to understand the business value that was intended and ensured that they produced just enough documentation in just enough time. These actions constituted acts of interessement on the business analysts who were resisting playing accordingly in their new envisaged roles in Scrum.

In the interview, the Scrum Master who had previously been a project manager indicated that he had done a lot of explaining and motivating for the adoption of Scrum with the aim of getting all stakeholders to buy into the idea. This was another strategy of interessement. The Scrum Master was quoted as follows:

"It was important that we make use of every
opportunity to educate people about Scrum. I
remember vividly spending hours with
developers debating about the need to go
through all this trouble of Scrum. In my mind
at the time I knew that this was a developer
thing, to sit lone with code silently and trying
to get it to work. What they were really
running away from was the fact that they
would no longer be on their own. In all that I
saw an opportunity to explain and motivate.
Trust me; I have had few of such debates from
the development team" (The Scrum Master:
IM).

The aim of the Scrum master/project manager was to get all actors to be on the same level of understanding of Scrum. This is in line with [43] who emphasises the importance of agreement amongst stakeholders where the stakeholders who have already become actors, translate their interests in order to enroll other stakeholders.

\subsection{Enrolment}

In this section the researcher discusses the roles proposed or imposed on each actor by the key actor 
referred to as enrolment in ANT. There were two significant aspects of enrolment in the network at IM: (1) it involved people with influence in terms of the hierarchy in the organisation and (2) it had gained strength as a result of the fact that most actors in the network strongly believed that Scrum would work.

The network was already strong and stable, it, therefore, was difficult for any stakeholder not to become part of the network as this would have made them feel isolated because they realised that Scrum would be adopted with or without them. The members of the development team were enrolled because of their responsibility in the team. Through the assistance of the Scrum consultant, the business analysts got to understand the new approach to their roles and were also eventually enrolled. This new approach brought comfort to the business analysts, which was another instance of enrollment in the actor network. The role that they played in the waterfall method was re-defined and they accepted the fact that they would no longer have to produce the lengthy documentation containing unnecessary functionality.

Another form of enrolment was the division of the 23 member team into two. In dividing the team the key actor tried to balance the skills in each team. At this point team members were enrolled at least to a team. They had a sense of belonging and feeling that they are still needed. Team members were informed that they would maintain their respective roles although Scrum prescribes that team members should not be addressed by their roles but as team members. This was yet another form of enrolment.

Similarly the CIO's role as the one who had officially introduced Scrum to the organisation can also be seen as enrolment. His role in the network was clear; introducing Scrum to the organisation and sending out all official communication regarding Scrum. The training was yet another enrolment agent. After training all actors understood their roles in Scrum. At this stage, every stakeholder had become an actor in the network. The roles for all stakeholders were clear.

\subsection{Mobilisation}

This is the final stage of translation and is the stage where the key actor is represented by poke-agents authorised to speak legitimately on behalf of the rest of actors. All actors who would speak against the network are silenced and the network is strengthened and stabilised. The aim is to keep actors focused on the main objective of the network. The extent of mobilisation determines the extent of success of the adoption. The agents of mobilisation in the network are discussed as follows:

The Scrum Consultant: At IM the Scrum consultant was the most conspicuous spokes-agent in the network. He gave direction and guidance as to what needed to be done. He also made suggestions on how best to implement Scrum. The consultant coached all members of the Scrum team, the Scrum master and, the product owner.

Six months after scrum was implemented, the scrum consultant visited IM to determine whether or not the actors were acting according to what was agreed upon in the enrolment moment and rectify any deviations if at all. The consultant's visit reemphasised his role as a spokes-agent. His role as a spokes-agent was key to the success of the adoption of Scrum.

The Scrum Forum: This was another spokesagent that was very influential in the mobilisation of the actors in the network. The aim of this forum was to discuss challenges and to share new developments pertaining to the Scrum method of systems development. In some cases an external Scrum consultant would be invited to share his experiences, new developments and answer questions. This forum proved to be a very effective spokes-agent. Instead of actors speaking negative about Scrum, they rather raised their concerns during the forums. These Scrum forums were well attended by all interested parties. Being an actor in the network for the adoption of Scrum became a pride in the organization.

Through these forums other business areas that had not adopted scrum became interested in this new methodology for systems development insomuch that at the time of conducting interviews for this thesis, the BPM domain was preparing for the adoption of scrum.

Problems: The problems (predictability, quality and productivity) that drove the domain owner to initiate the adoption of a new methodology of systems development were also agents that the Scrum consultant kept reminding the team about. These problems were also the focus of the business. The actors in the network were very keen to see how Scrum would address these problems.

Scrum Roles and Responsibilities: Scrum, its roles and responsibilities were spoke-agents in the network as well. All actors enrolled in the network and allocated roles were reminded about their responsibilities by virtue of being in the network. The mobilisation was more emphatic on the Scrum team because they held daily stand-up meetings. Scrum has six roles which are based on the definition by [12]. These roles are Scrum master, 
product owner, Scrum team, customer, user and management.

Scrum Practices and Tools: As mentioned in Section 2, Scrum is based on the use of certain management practices and tools. These are applied in various phases of Scrum. These tools help in avoiding chaos that can be brought about by complexity and unpredictability. The tools used in IM include product backlog, effort estimation, sprint, sprint planning meeting, sprint backlog, daily scrum meeting, sprint review meeting, Sprint retrospective meeting, stories, Burn-down chart, Small Scrum team, Scrum team sitting together and Impediment list.

\section{- Highlights of Mobilisation}

The Team Members: The domain owner together with the development teams decided to retain their role names and not change to team members. They argued that if they changed to be team members that would bring confusion to the team and to the business. They maintained their role titles, for example, business analyst, developer, network specialist, and so on. The team further noted that the changing of their role names to team members would further undermine their areas specialisation. In addition, if a new member was needed to join the team it would not be clear as to what skills were required. This implies that South Africans enjoy having clearly delineated roles and that is one of the possible reasons why they would not like to be called team members. This is regarded as a cultural influence.

Another important aspect pertaining to teams is the seating arrangement. Scrum prescribes that teams sit in such a way that face-to-face communication is encouraged. In the case of IM, the only change that was implemented was to move team members close together. Members still maintained the privacy. The environment did not really encourage face-to face communication as emails were still used. Another reason, as stated by the interview respondents, was that people still believed that they need to cover their backs. This means that there was no absolute trust amongst the members. Emails were seen as a way of keeping a record of what was communicated and when it was communicated. Trust is another cultural aspect that team members still need to develop.

Scrum master: Scrum prescribes that a Scrum team needs to have at least one dedicated Scrum master. It was not the case at IM. There was one Scrum master that was shared by the two Scrum teams. The reason for this is that there were limited resources and there was a need for more skills within the teams. This is due to the fact that there are not enough resources trained in agile environments in South Africa [28]. One Scrum master fulfilled the Scrum master role for both teams in IM.

Product Backlog and Sprint: At IM, there was no product backlog; instead, the project was broken into smaller sub-projects according to functionality. The teams and the product owner still worked with traditional project plans. The difference was that their project plans were made visible to all team members. From the project plan they selected what made up a sprint. A sprint in their case was a subproject that a team could complete in two weeks. The team divided the tasks amongst themselves.

Small teams: As one of the key aspects, Scrum prescribes that a Scrum team should be made up of between five to nine members [28]. Before the adoption of Scrum at IM, the development team was made up of twenty-three members with different specialisations. The Scrum consultant, therefore, split the original development team into two teams to work independently and focus on different projects. One team had eleven members while the other was made up of twelve members. We can already identify the fact that even though Scrum prescribes a maximum team size of nine it is not always possible.

Visual Tools: Scrum's visual tools include the sprint backlog, the burn down chart and the impediment list, which were embraced at IM and adopted as they were. IM online domain believed that project progress should be visible to all stakeholders. They also believed that this approach would also contribute positively to the progress of the team. This would eliminate activities that were not attended to until the last minute. The visual tools were also seen as tools for monitoring individual progress against time.

Benefits associated with Adoption of Scrum: The Online domain owner indicated that they got more than they expected from the adoption of scrum.

"Quality has improved exponentially. We have fewer defects and we are much better at delivering on our promises. Teams are a lot more productive. An added bonus was that partnership between business and IT grew", (Online Domain Owner: IM).

The adoption of scrum has addressed the problems that online domain at IM had. One can also draw from the domain owner that they received more benefits than they hoped for. This shows that Scrum when implemented correctly, it can bring amazing results. 


\subsection{Irreversibility}

It became difficult to abandon the adoption owing to the actor network having been established and strengthened [37]. At this stage, the network was stable and could be regarded as having reached an irreversible stage. The network elements were so strongly connected that it would have been almost impossible to revert back to the old methodology of systems development.

According to [37], irreversibility is also born by strong inscriptions, in this case the inscriptions by the Scrum consultant. The presence of the Scrum consultant contributed to the state of irreversibility; he was experienced and was able to spot the problem areas and deal with them appropriately. This made Scrum implementation a smooth process.

\subsection{Inscription}

Inscription is a process of creating artifacts to ensure protection of actors' interests [35]. The CIO ensured that the vision of producing quality software was fulfilled by providing funding and by presenting the idea to the rest of the organisation. On the other hand, the Scrum consultant provided coaching and guidance during the adoption of Scrum in a manner that would not prejudice any of the actors. Both of these are forms of inscription.

The pledged support from the Executive team and the CIO for the adoption of Scrum was a strong inscription. Due to their promises and power hierarchies, stakeholders were willing to join the network. The involvement of the CIO, either by communicating the progress of scrum or visiting the systems development team, though an inscription on their own, made the actors feel that their interests were protected and thereby being inscribed.

During the process of adopting Scrum, the involvement of a Scrum consultant facilitated a smooth transition from the waterfall method of systems development to Scrum. It is also important to note that IM did not adopt all aspects of Scrum, but rather selected those aspects that would address their problems. The implementation of Scrum at IM yielded better results than was expected. To get to a stage where Scrum was adopted, some alignment of stakeholder interests had to take place. Actors went through a process negotiations, reinterpretation and translation of interest in order to enroll other actors.

\section{FINDINGS, DISCUSSIONS AND INTERPRETATIONS}

This Section discusses the findings that emerged from this research study. It also attempts to interpret the findings. One organization was used in this investigation since it is correct for one to generalise on a single case study and that it is an appropriate and valuable approach. It would however, be incorrect to ascertain that this is the only way to work. Selection of this case was purposive because this particular case represented a bigger population in investment management and online business domain prevalent in South Africa [44].

The organization where the study was conducted is of South African origin. Even though it grew to have branches in Botswana, Swaziland and London, the head office in South Africa still had influence on the other branches. This makes this organisation a true representation of South African organisations.

It is evident from the analysis that even though agile methods of systems development may be an attractive approach to use; organisations need to understand their needs in order to be able to choose only those aspects of agile that best address the organisation's needs.

\subsection{IM and Technology}

It was found that some organisations cannot operate without IT; they, therefore, need to continuously improve the quality of systems they need to deliver the business objectives. Owing to frequent market changes, there is a need for organisations to deliver systems to the business quickly to keep abreast with the changes. Scrum helps in addressing this need; it delivers most needed functionality within a short period of time. This finding answers the question on the extent South African organisations rely on IT to revelage their competitive advantage.

If we look at the history of Toyota as one of the pioneers of the agile approach, we see that the organisation identified the need to eliminate wasteand to produce only what was required [45]. In adopting this approach, they were moving away from mass production in order to reduce costs. IM also has a similar history of delivering huge software projects. They needed to be more agile in their approach so that they are able to reduce costs and adapt quickly to changes in the market.

This study reveals that IT expenditure must be justifiable. Accordingly, an agile approach to systems development can help by delivering working software within a short period of time. This enables the businesses to realise a quicker return on investment (ROI). This finding is in line with the study conducted by [28] that indicates that the problems experienced by software development companies in South Africa include late releases, cost overruns, resource constraints and lack of understanding of business requirements. 
The finding contributes to the agile body of knowledge by uncovering the major problems in additions to late release, cost overruns, resource constraints and poor understanding of business requirements that South African organisations experience during software development. These problems are quality of software, systems development team productivity and cohesiveness, and dependability of the systems development team. These problems can be resolved by the use of Scrum in a South African context.

\subsection{Preparation for Adoption}

Another finding is that in preparing to adopt agile software development methods, organisations go through a process of trying to reach a point of common understanding of the problems. Thereafter, stakeholders (IT department and the business) need to work together in crafting solutions to the problems even prior to the adoption. Agile methods require collaboration among stakeholders [7]. When stakeholders do not have a common idea of the solution to be adopted and pursue independent agendas, adoption of agile methods of systems development fail. The finding gives an answer on how organisations prepare for the adoption of agile software development methods. The findings might be relevant to both South African and other international organisations.

This finding makes two contributions. (1) The adoption of agile methods of software development was triggered by the existence of problems. These problems included poor quality of software resulting into not delivering functionality as promised and project overruns. Some of the problems are associated with the fact that IT departments cannot keep up with market changes. These problems render the stakeholders dissatisfied. These findings hit on stakeholder satisfaction. Stakeholders need to be aware of problems that prevail although they might not have solutions to such problems. In preparing to address the problems, stakeholders need to have a common understanding. The importance of common understanding is a recurrent theme in the study. At several occasions problematisation failed because the stakeholders did not have a shared view of both the problems and the intended solution. It can be concluded therefore that a successful scrum adoption, a common understanding and view of the methodology is a must.

(2)Before adopting agile methods of systems development, there is a need to establish a common understanding of the problems that need to be addressed using the specific agile approach to systems development. This means that much as the stakeholders need to be aware of problems they, (stakeholders) should be willing to be part of finding solutions. In this way stakeholders are strongly committed to the agenda of the network.

\subsection{The Process of Adoption}

In answering the research question "What processes are followed in the actual adoption of agile methods of systems development?" the study found that the adoption of agile methods, in particular Scrum, is a process requiring careful management. Due to the unavailability of an agile adoption framework, organizations adopting agile go through three phases: Pre adoption phase, adoption phase and post adoption phase. This is the gap that was identified in literature. The gap was that there was no study conducted on the process that South African organisations follow when adopting agile methods of system development.

The adoption process involves: firstly, getting the stakeholders on the same level of understanding that there is a problem that needs to be addressed, secondly, agree on the methodology that will be used to address the problem, and thirdly, adopt and check if the problems have been addressed. This gap has been bridged.

The adoption process was found to have three challenges namely; (1) organisational culture, (2) trustworthiness of the methodology to be adopted, and lack of knowhow in the implementation of the methodology and (3) resistance to change. If challenges prevail during any phase of agile methods adoption, they may lead to abandonment of the adoption process. These challenges are explained in the subsequent sub-sections.

1. Organisational Culture in South African organisations is rarely considered in adoption of new systems development methods and yet it plays a major role. Another challenge that emerged is that employees fear the unknown and resist change because they do not want to move out of their comfort zones.

2. Organisations need guidance during adoption and proof and assuarance that the methodology is trustworthy. This was the service provided by the Scrum consultant at IM. Management involvement and approval is also crucial to the adoption of Scrum. Such involvement could take the form of management formally introducing the methodology to employees of the organisation. This shows that they approve 
of it and that makes the rest of the organisation trust it. Other approaches failed because this approach was not followed.

3. It is easier to introduce an agile methodology such as Scrum to an organisation when the business processes are quite new and can thus be easily reshaped and mapped on top of the methodology. This has been the case at IM. People had not been acquainted with the processes and therefore there was nothing heavily entrenched in their way of doing things.

There is no structured approach to the adoption of agile methods of systems development [22]. Although organisations may make attempts to adopt agile methods, they may not get it right, as it takes determination to succeed. The use of consultants can help in getting it right the first time.

A complimentary contribution is that consultants should be considered when adopting agile methods of systems development. This allows the organisation to involve an objective approach to the process of adoption. Using internal resources to implement agile methodology would expose the process to subjectivity. It is also important to engage the stakeholders in finding the method to be used. Again this is a contribution towards practice.

\subsection{Aspects of Agile Adopted by South African Organisations}

The study also found that in adopting Scrum as an agile method of systems development, organisations select only those aspects of the method that address the problems they experience.

IM did not follow the exact prescription of Scrum method; rather the method was customised to suit the unique circumstances of IM. The nature of the environment, the resource constraints and the problems that are being addressed by adopting agile methods are key determinants of the aspects IM adopt [19]. IM was focused on addressing the problems at hand. This also lightened the burden of adopting the new methodology.

This finding also makes a practical contribution. Organisations need to understand their problems before they engage in the adoption process. In addition they need to have good understanding of the methodology they will use. This would put them in a better position to pick aspects of the methodology that would best address their problems. The end results would be a lighter adoption process as there is no need to change aspects that deliver objectives. This is line with [46] who states that systems development teams use parts of methodologies and do not follow all the steps required by a particular methodology. This finding also answers the research question "Do South African organizations comply with agile principles as embodied by agile methodologies while developing systems?"

As indicated, predictability, quality and productivity were identified as main problems that forced the IT department to seek new ways of systems development. In IM, the Consultant was interested in seeing to it that the adoption of agile methods of systems development did indeed address these problems. In selecting appropriate aspects of Scrum, the focus was on breaking down of one big team into two small teams that focused on different projects. This aspect of Scrum addressed the problem of productivity. The teams became more productive. Another aspect that was embraced was the iterations approach to systems development. This aspect encouraged learning within short periods of time and thereby improving quality of software. It also encouraged delivery of working software within a sprint; this improved predictability in IM.

Methodologies are the tools used to develop information systems in order to get the job done [47, $48,49]$. This is also the case with the South African organisations; they focused on solving the problems rather than the methodology itself. In the case of the case study organization, this focus was made possible by the use of external consultant who would focus on the methodology while the development team focused on getting their problems resolved.

Agile methods may address many of the problems associated with systems development in the South African context. However, there is no single methodology that can address all these problems. South African organisations need to focus on adopting aspects that will address their problems.

\section{CONCLUSION}

The goal of this study was to provide an understanding of what phases South African organisations go through in their attempt to adopt agile methods of systems development. Because the researcher had to look, amongst other things at the relations between the stakeholders, ANT was used as a research approach. The ANT traces the way relationships are formed amongst stakeholders during the adoption of agile methods. ANT was used to explain complex relationships among stakeholders in scientific research settings [36]. It 
also provided a comprehensive approach for tracing the way interests of stakeholders are aligned [41].

South African organisations need to understand the benefits they can obtain by adopting agile methods of systems development. One of the findings, amongst others, from IM case is that adoption of agile methods by South African organisations is driven by problems that prevail within the IT department. Owing to the business's dependence on IT, IT is pressurised to improve the quality of the systems it develops. Frequent market changes also compel IT to deliver systems to the business quickly in order to keep up with those changes. In the case of IM Scrum has contributed to the resolution of those problems.

There is an absence of an agile adoption framework applicable to the South African context. This makes the adoption of agile methods by South African organisations unstructured. It has been revealed, therefore, by the study conducted at IM that in adopting agile methods of systems development, South African organisations go through three phases; the pre-adoption phase, adoption phase and the post-adoption phase. These phases need to be managed carefully to realize a successful adoption.

There are also challenges that are experienced during the adoption of agile methodologies. Many of these challenges relate to people and the organisational culture and reveal that South African organizations need to manage the transition from traditional methodologies carefully. It is important to get stakeholder buy-in in order to succeed in the adoption of agile methodology.

It has also been found from this study that South African organisations do not adopt agile methods as prescribed; rather they select aspects of agile methods that will address the problems that they experience in their organisations. This is in line with the findings of [46] who states that systems development teams use parts of methodologies and do not follow all the steps required by a particular methodology [46].

Adoption of agile methods in South Africa is on the rise but there is no structured approach to adopting these methods. The absence of structure in the approach organisation follow could expose them to abortive adoptions. For future research, there would be value in developing a framework that would make it easy for South African organisations to adopt agile methods. This framework would reduce the chances of failure during the adoption of agile methods.

There is a move by organisations away from the traditional methods of systems development to agile methods. Although some organisations may aspire to this kind of move, the obstacle to such a move is a lack of empirical evidence as to what processhave been followed by other organisations in South Africa.This research has spelt out the problems encountered by organisations in adopting agile methods.

The purpose of the study was to provide organisations with empirical evidence of the steps to be followed by when adopting agile methods of systems development. This will equip organisations with an understanding of the challenges that organisations face when adopting agile methods in South Africa.

\section{REFERENCES}

[1] Ismail, H.S., Snowden, S.P., Poolton, J., Reid, I.R. \&Arokiam, I.C. (2006). Agile manufacturing framework and practice. International journal of agile systems and management 1(1), 11-28.

[2] Qumer, A. \& Henderson-Sellers, B. (2008). An evaluation of the degree of agility in six agile methods and its applicability for method engineering. Information and software technology, 50(4), 280-295.

[3] Chan, F. K. Y. \& Thong, J. Y. L. (2008). Acceptance of agile methodologies: A critical review and conceptual framework (pp. 1-2). Hong Kong, Elsevier.

[4] Syed-Abdullah, S., Holcombe, M. \&Gheorge, M. (2007). The impact of an agile methodology on the well being of development teams. Empirical Software Engineering, 11, 145-169.

[5] Henderson-Sellers, B. \&Serour, M. K., (2005). Creating a dual agility method: The value of method engineering. Journal of database management, 16(4), 1-24.

[6] Highsmith, J. (2002). Agile software development ecosystems. Boston, MA: AddisonWesley (Pearson Education).

[7] Maurer, F. \&Melnik, G. (2007). Agile methods: Crossing the chasm. 29th International conference on software engineering, 1-2.

[8] Kettunen, P. (2008). Adopting key lessons from agile manufacturing to agile software product development: A comparative study. Technovation, 6(2), 45-75.

[9] Hughes, B. \&Cotterell, M. (2006). Software project management (4th ed.). London, UK: McGraw-Hill. 
[10] Pressman, R. S. (2005). Software engineering: A practitioner's approach (6th ed.), New York, McGraw-Hill.

[11] Beck, K. (1999). Embracing change with extreme programming. IEEE Computer, 32(10), 70-77.

[12] Schwabe, K. \&Beedle, M. (2002). Agile software development with Scrum (series in agile software development) (14ed). Reading, MA: Addison Wesley.

[13] Abrahamsson, P., Salo, O., Ronkainen, J. \&Warsta, J. (2002). Agile software development: A review and analysis. Retrieved 13 May 2009, 2009, from http://www.vtt.fi/inf/pdf/publications/2002/P47 8.pdf

[14] Boehm, B. \& Turner, R. (2004). Balancing agility and discipline: A guide for the perplexed. Boston: Addison-Wesley (Pearson Education).

[15] Nerur, S., Mahapatra, R. \&Mangalaraj, G. (2005). Challenges of migrating to agile methodologies. Communications of the ACM, 48(5), 73-78.

[16] Cohn, M. \& Ford, D. (2003). Introducing an agile process to an organisation. IEEE Computer society, 74-78.

[17] Cockburn, A. \&Highsmith, J. (2001). Agile software development: The business of innovation. Computer, 16, 120-122.

[18] Berteig, M. (2007). Agile benefits: Five essential reasons to try agile. Retrieved June, 2009, from http://www.agileadvice.com/archives/2007/09/a gile benefits 1. html

[19] Longden-Thurgood, R. \& Mackintosh, C. (2007). How structured are agile practices?BCom (Hons), University of Cape Town, pp. 1-73.

[20] Rising, L. \&Janoff, N. S. (2000). The Scrum software development process for small teams. IEEE SOFTWARE,17(4), 2-8.

[21] Mahanti, A. (2006). Challenges in enterprise adoption of agile methods: A survey. Journal of computing and information technology: CIT, 14(3), 197-206.

[22] Sidky, A. \& Arthur, J. (2007). A disciplined approach to adopting agile practices: The agile adoption framework. Virginia: Virginia Tech.

[23] Highsmith, J. (Ed.). (2004). Agile project management: Creating innovative products. New York: Addison-Wesley professional.
[24] Boehm, B. \& Turner, R. (2009). Management challenges to implementing agile processes in traditional development organisations. Boston: Addison-Wesley.

[25] Tolfo, C. \&Wazlawick, R. S. (2008). The influence of organisational culture on the adoption of extreme programming. Journal of systems and software, 81(11), 1955-1967.

[26] Vijayasarathy, L. R. (2008). Agile software development: A survey of early adopters. Journal of information technology management, XIX(2), 1042-1319.

[27] Ferreira, C. \& Cohen, J. (2008). Agile systems development and stakeholder satisfaction: a South African empirical study. SAICSIT 2008 conference, 6 - 8 October 2008, Wilderness Beach Hotel, Wilderness, South Africa, 48-55.

[28] Friedrich, W. R. \& van der Poll, J. A. (2007). Towards a methodology to elicit tacit domain knowledge from users. Interdisciplinary journal of information, knowledge, and management, 2,180-193.

[29] Tanner, M. C. (2006). Culture and communication in global software development, Cape Town: University of Cape Town.

[30] Law, J. (1991). A sociology of monsters: Essays on power, technology and domination. London: Routledge.

[31] Latour, B. (Ed.). (1987). Science in action: How to follow scientists and engineers through society. Cambridge, MA: Harvard University Press.

[32] Callon, M. (1986a). Some elements of sociology of translation: domestication of the scallops and the fishermen of St Brieux Bay. In J. Law (Eds.), Power, action \& belief: A new sociology of knowledge? (pp. 196-229).

London: Routledge\&Kegan Paul.

[33] Callon, M. \&Latour, B. (1981). Unscrewing the big leviathan: How actors macro-structure reality and how sociologists help them to do so. Advances in social theory and methodology, 277-303.

[34] Callon, M. (1991). Actant-networks. Retrieved 13, May, 2009, from https://tspace.library.utoronto.ca/citd/holtorf/3.1 1.html

[35] Latour, B. (1992). Where are the missing masses? The sociology of a few mundane artifacts. In W. E. Bijker\& J. Law (Eds.), Shaping technology/building society: Studies in 
sociotechnical change, London, England, (pp. 225-258).

[36] William-Jones, B. \& Graham, J. E. (2003). Actor-network theory: A tool to support ethical analysis of commercial genetic testing. New genetics and society, 22(3), 271-296.

[37] Mpazanje, F. T. H. (2009). Towards understanding as-lived experiences in information systems projects: An actor-network theory perspective. Unpublished masters information systems, University of Cape Town.

[38] Nijland. (2004). Understanding the use of IT evaluation methods in organisations. $\mathrm{PhD}$ Thesis, London school of economics and political science.

[39] Callon, M. (1986b). Some elements of sociology of translation: Domestication of the scallops and the fishermen of St Brieux bay. Power, action and belief: A New sociology of knowledge, 196-223.

[40] Tanner, M., \&Chigona, W. (2010). Information Infrastructure Development: A South African SME ANT Perspective, 4th IDIA Conference, 3rd-5th November, Cape Town, South Africa [ISBN: 978-0-620-47590-7

[41] Mahring, M., Holmstrom, J., Keil, M. \&Montealegre, R. (2004). Trojan actor-network and swift translation: Bringing the actornetwork theory to IT project escalation studies. Information technology and people, 17(2), 210238.
[42] Callon, M. (1996). Techno-economic networks and irreversibility: Technology and domination (pp. 132-161). London: Routledge.

[43] Vaagaasar, A. N. (2006). From tool to actor: How a project came to orchestrate its own life and that of others. Degree of Dr.Oecon, BI Norwegian school of management.

[44] Lee, A. S. \& Baskerville, R. L. (2003). Generalizing generalisability in information systems research. Information systems research, 14(3), 221-243.

[45] Poppendieck, M. \&Poppendieck, T. (2003). Lean software development: An agile toolkit. Boston, MA: Addison-Wesley (Pearson Education).

[46] Fitzgerald, B., (1996). Formalised systems development methodologies: a critical perspective. Information systems journal, 6 (1), 3-23.

[47] Jantsch, E. (1980). Self-organizing universe: Scientific and human implications of the emerging paradigm of evolution. Oxford: Pergamon Press.

[48] Prigogine, I. \&Stengers, I. (1985). Order out of chaos. New York: Bantam Books.

[49] Von Foerster, H. (1984). Principles of selforganisation: In a socio-managerial context. Berlin: Springer. 